\section{We need more prospective studies for Kounis syndrome}

To the Editor: We read the article ${ }^{[1]}$ about Kounis syndrome published in an earlier issue of your journal with great interest. This letter is intended both to correct a mistake in the article and to emphasise its importance by sharing our own clinical experiences.

Kounis syndrome, which is a myocardial ischaemia picture accompanying allergic cases, was first described in 1991. ${ }^{[2]}$ Though not rare, Kounis syndrome is among the diseases less commonly found in literature, and one of the least known and most underdiagnosed diseases by clinicians. ${ }^{[3]}$ Actual incidence of the disease is not exactly known, because of poor reliability in reporting and misdiagnosis. ${ }^{[3,4]}$

The incidence of the disease was indicated to be between 4.3 and 9.6 per 100000 in retrospective studies. ${ }^{[5,6]}$ Only one study shows the prospective incidence of Kounis syndrome, ${ }^{[3,7]}$ conducted in our institution. In this study, Akoz et al. ${ }^{[7]}$ found the incidence of the disease to be 19.4/100 000. ${ }^{[7]}$ This incidence is high compared with retrospective studies, indicating that the syndrome is actually more common than estimated. Unfortunately, this prospective study was mistakenly stated to be retrospective in the letter published in your journal. ${ }^{[1]}$

Although Kounis syndrome is found in all races and age groups across the world, ${ }^{[1]}$ the number of the reported cases from southern European countries is relatively high. ${ }^{[5]}$ Factors such as genetic predisposition, similar climatic and environmental conditions, inaccuracies in drug use and higher clinician awareness of the disease in that region may contribute to the differences in geographical distribution. ${ }^{[5]}$ With this letter, we particularly want to thank the respected scientist Dr Kounis, who contributed to awareness of the syndrome among clinicians. Along with an increase in publications about Kounis syndrome, it is possible that there will be an increase in reported cases of the disease in African countries. Symptoms and/or findings of systemic allergic response accompanying electrocardiographic or laboratory findings of myocardial ischaemia should remind us of the possibility of Kounis syndrome. ${ }^{[8]}$ However, sometimes Kounis syndrome can be observed without classic clinical findings of hypersensitivity such as skin lesion (urticaria, angiooedema, mucosal involvement) or hypotension. ${ }^{[7]}$

The diagnosis of the syndrome is made primarily via symptoms and signs, electrocardiographic and laboratory features, and echocardiographic and angiographic changes in patients. ${ }^{[3]}$ Our prospec- tive study showed that cardiac magnetic resonance imaging (MRI) can also be used as an alternative to these methods, ${ }^{[7]}$ especially in patients who have contrast allergy or who need to be careful about radiation exposure. Cardiac MRI is successful in the early diagnosis of the syndrome, making the disease diagnosable in individuals whose electrocardiogram and troponin are normal, distinguishing between ischaemic and non-ischaemic cases. ${ }^{[7]}$ Although cardiac MRI use is not common in emergency services, we want to remind again that it has a place in the diagnosis of Kounis syndrome.

There are three variants of Kounis syndrome, depending on whether there is a lesion in the coronary artery or if there is a drugeluting stent in the patient. ${ }^{[3]}$ In the treatment stage, although there are some differences in the variants, it is difficult to know which exact type of Kounis syndrome the patient has during the first evaluation of an individual at emergency services. Thus, early patient treatment should include management of acute coronary syndrome and alleviation of the allergic symptoms. ${ }^{[9]}$

In conclusion, we believe that doctors in Africa will increasingly diagnose Kounis syndrome in the future, as current experience in dark-skinned patients is very low.

\section{Akbas, M Emet}

Department of Emergency Medicine, Faculty of Medicine, University of Ataturk, Erzurum, Turkey

mucahitemet@gmail.com

1. Kounis NG, Grapsas N, Lianas D, Soufras GD, Patsouras N. Kounis syndrome: Aspects of incidence and epidemiology. S Afr Med J 2016;106(5):426. DOI:10.7196/samj.2016.v106i5.10680

Kounis NG, Zavras GM. Histamine-induced coronary artery spasm: The concept of allergic angina. B J Clin Pract 1991;45(2):121-128.

3. Kounis NG. Kounis syndrome: An update on epidemiology, pathogenesis, diagnosis and therapeutic management. Clin Chem Lab Med 2016;54(10):1545-1559. DOI:10.1515/cclm-2016-0010

Scherbak D, Lazkani M, Sparacino N, Loli A. Kounis syndrome: A stinging case of ST-elevation Scherbak D, Lazkani M, Sparacino N, Loll A. Kounis sy DOI A stinging case of ST-el

Kounis NG, Mazarakis A, Tsigkas G, Giannopoulos S, Goudevenos J. Kounis syndrome: A new twist Kounis NG, Mazarakis A, Tsigkas G, Giannopoulos S, Goudevenos J. Kouni
on an old disease. Future Cardiol 2011:7(6):805-824. DOI:10.2217/fca.11.63

on an old disease. Future Cardiol 2011;7(6):805-824. DOI:10.2217/fca.11.63
Helbling A, Hurni T, Mueller UR, Pichler WJ. Incidence of anaphylaxis with circulatory symptoms: A study over a 3-year period comprising 940,000 inhabitants of the Swiss Canton Bern. Clin Exp Allergy 2004;34(2):285-290. DOI:10.1111/j.1365-2222.2004.01882.x

7. Akoz A, Tanboga HI, Emet M, et al. A prospective study of Kounis syndrome: Clinical experience an cardiac magnetic resonance imaging findings for 21 patients. Acta Medica 2013;29:811

8. Fourie P. Kounis syndrome: A narrative review. S Afr J Anaesth Analg 2016;22(2):72-80. DOI:10.108 0/22201181.2016.1154309

9. Gunaydin ZY, Bektas O, Akgedik R, Kaya A, Acar T. Recurrent Kounis syndrome. How should be the long-term treatment of Kounis syndrome? Int J Cardiol 2014;177(3):1042-1043. DOI:10.1016/ ijcard.2014.11.048

S Afr Med J 2016;106(11):1060. DOI:10.7196/SAMJ.2016.v106i11.11190 